\title{
Phytochemical investigation on various parts of Psidium guajava
}

Lincy Joseph ${ }^{*}$, Mathew George ${ }^{2}$, Gurcharan Singh ${ }^{3}$, Prabha Mathews ${ }^{4}$

${ }^{1}$ Department of Pharmaceutical Chemistry, Pushpagiri College of Pharmacy, Medicity, Thiruvalla, Kerala, India. 2Department of Pharmacology, Pushpagiri College of Pharmacy, Medicity, Thiruvalla, Kerala, India.

${ }^{3}$ Gurcharan Singh, Department of Pharmaceutical Chemistry, School of Pharmaceutical Sciences, Jaipur National

University, Jaipur, Rajasthan, India.

${ }^{4}$ Department of Pharmaceutical Chemistry, Pushpagiri College of Pharmacy, Medicity, Thiruvalla, Kerala, India.

Received: December 22, 2015; Revised: January 12, 2016; Accepted: January 21, 2016.

\begin{abstract}
The objective of the study was to perform phytochemical screening of alcoholic and aqueous extracts of leaves, seeds and fruit pulp of Psidium guajava, to isolate the active principles by column chromatography and to characterize the isolated compound by chemical tests and IR spectroscopy. The phytochemical investigation was performed to identify the presence of glycosides, flavanoids, alkaloids, saponins, vitamin, tannins, carbohydrate, amino acid, steroid in the extracts, which showed phytoconstituents in various proportions in aqueous and alcoholic extracts of seeds, fruit pulp and leaves of Psidium guajava. Leaf extract showed the presence of maximum number of phytoconstituents and alcoholic fruit pulp extract showed minimum constituents. Alcoholic seed extracts were subjected to column chromatography and qualitative chemical test and IR spectroscopy of the isolated compound showed that the compound may be a steroidal glycoside or the compound has a steroidal nucleus with a lactone ring.
\end{abstract}

Key words: Aqueous leaf extract; column chromatography; phytochemical screening; Psidium guajava, Soxhlet extraction; steroidal lactone.

\section{Introduction}

Medicinal plants are used in different countries as sources of many potent and powerful medicines. Psidium guajava is a small evergreen sub deciduous tree (Ali Mohammad, 2008). It is found in tropical and subtropical areas (CSIR, 2006). It is a native of tropical America (Antony D.C, Dwek Data). Guava fruit is still enjoyed as a sweet treat by indigenous peoples throughout the rainforest and the leaves and bark of the guava tree has a long history of medicinal uses that are still employed today. The leaves and barks of guava is used as a cure of diarrhea (Ojewole et al., 2008), sore throat, vomiting, stomach upset, vertigo etc. In a recent study with guinea pigs Brazilian researches reported that guava leaf extract has numerous effect on cardiovascular system (Gondim, 2009). Other animal studies showed that guava leaf extracts have analgesic, sedative and CNS depressant activity. The taxonomical classification of the plant Psidium guajava is as follows

Kingdom: - Plantae

Order:- Myrtales

Family:- Myrtaceae

Subfamily: - myrtoideae

Genus:- Psidium

Species: - guavajava

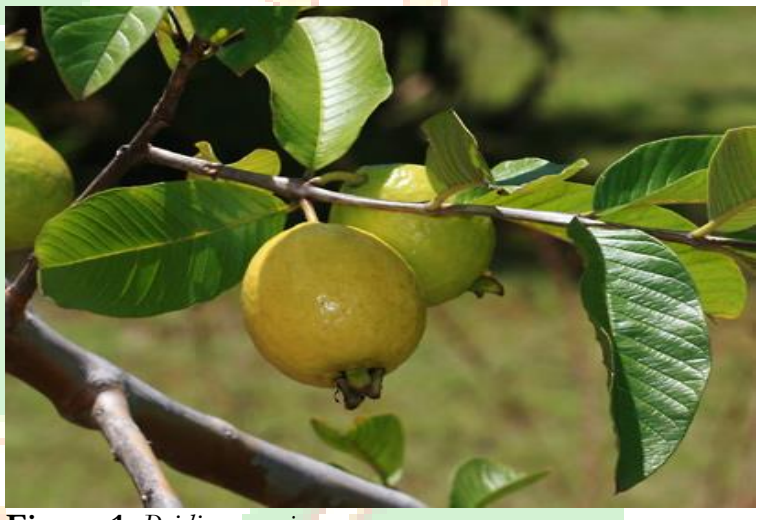

Figure 1: Psidium guajava

Literature reviews showed that guava is rich in tannin, phenols, flavanoids, saponins, carotenoids, vitamins, fiber and fatty acids. Guava fruit is rich in Vitamin-C. Aim of the present study is to perform phytochemical analysis of aqueous and alcoholic extracts of various parts of psidium guajava and isolate active principles by column chromatography, to characterize the isolated compound.

\section{Materials and Methods}

Method of Collection of plant: The tender leaves and fruit of the plant Psidium guajava were collected in the month of November 2009 from Agriculture Research Institute Durgapura, Jaipur, (Rajasthan). Authentication of the plant was done in the Department of Botany, Rajasthan University, Jaipur (Rajasthan) under registration no. 20608.

Preparation of sample: The tender leaves were dried in shade. The fruit of Psidium guajava without peel were boiled with water with gentle heating to 
avoid decomposition of the constituents. This procedure was carried out to separate seed from fruit pulp. After which seed and fruit pulp were dried in shade and were crushed to obtain a coarse powder.

Preparation of Extracts: The dried plant material were crushed into powder and were subjected to aqueous and alcoholic extraction using soxhlet extraction method. First the sample material was extracted with petroleum ether after which the samples were extracted with distilled water and $99.9 \%$ alcohol for a period of $24 \mathrm{hrs}$ until it becomes colourless. After extraction solvent was evaporated to dryness and percentage yield was calculated. This process was carried out separately for each selected plant part.

Phytochemical analysis: Freshly prepared extracts of tender leaf, fruit pulp, and seeds of Psidium guajava were qualitatively tested for presence of various phytoconstituents lik glycosides, flavanoids, alkaloids, saponins, vitamin, tannins, carbohydrate, amino acid, steroid (Khandelwa, 2006) and ethonolic seed extract was evaporated and isolated individual constituents by column chromatography and structure of active principles were characterized by chemical tests and IR spectroscopic analysis.

Fractionation of Ethanolic Seed Extract by Column Chromatography (Harborne, 1998): Column chromatography was performed on silicagel (60-120 mesh size) packed glass column for separating the phytochemical constituents present in ethanolic extracts of seed of Psidium guajava. Column made up of a simple straight glass tube $60 \mathrm{~cm}$ long was used having a diameter of $3.5 \mathrm{~cm}$. A glass wool plug was inserted into the bottom of the glass column which was previously rinsed with distilled water and dried. A slurry of silica gel prepared in petroleum ether was filled in the column and sample in dry form was filled on the adsorbent layer upto $5 \mathrm{~cm}$. solvent system was run into column and the flow rate was adjusted to 15 drops per minutes. The separation was carried out by successive elution. Sequence of solvents used in the increasing order of polarity is petroleum ether, petroleum ether-benzene, benzene, benzenechloroform, chloroform, chloroform- ethyl acetae, ethyl acetate, ethyl acetate-ethanol, ethanol, ethanolmethanol, methanol.
Characterization of isolated compounds was done by performing chemical test for flavonoids, glycosides, steroids, and by IR spectroscopic analysis using FTIR Spectrophotometer.

\section{Characterization of the isolated compound by} chemical tests.

Preparation of solution of isolate: $5 \mathrm{mg}$ of compound was weighed accurately and transferred to $50 \mathrm{ml}$ beaker and dissolved in $20 \mathrm{ml}$ ethanol.

\section{Test for flavanoid}

a. Lead acetate test: To $2 \mathrm{ml}$ of solution of isolate lead acetate solution was added and observed for the development of precipitate. Yellow coloured precipitate indicates the presence of flavanoids.

b. Sodium hydroxide test: To $2 \mathrm{ml}$ solution of isolate in test tube $\mathrm{NaOH}$ was added in increasing amount and observed for colour change. Formation of yellow colour indicates the presence of flavanoids.

Test for glycosides.

a. Keller Killani Test: To $2 \mathrm{ml}$ solution of isolate $1 \mathrm{ml}$ glacial acetic acid was added and then 1 drop $5 \% \mathrm{FeCl}_{3}$ was added. After it concentrated $\mathrm{H}_{2} \mathrm{SO}_{4}$ was added. Appearance of a reddish brown colour at the junction of the two layer indicates the presence of glycosides.

b. Legal test: To $1 \mathrm{ml}$ solution of isolate, $1 \mathrm{ml}$ sodium nitropruside was added. Appearance of pink colour indicates the presence of glycosides.

\section{Test for steroid}

Lieberman's reaction: Acetic anhydride was added to the isolate solution in a test tube. Then test tube was heated and cooled. After it few drops of concentrate $\mathrm{H}_{2} \mathrm{SO}_{4}$ was added. Presence of blue colour indicates the presence of steroid nucleus.

\section{Results}

Aqueous and alcoholic extracts of tender leaves, fruit pulp, and seeds of Psidium guajava were obtained by soxhlet extraction. Alcoholic extracts were obtained in more proportion compared to aqueous extracts (Table 1). Phytochemical screening of both aqueous and alcoholic extract showed the presence of glycosides, flavanoids, alkaloids, saponins, vitamin, carbohydrate, amino acid. The result of phytochemical screening is shown in Table 2.

Table 1: Aquoeus and alcoholic extraction of various parts of Psidium guajava

\begin{tabular}{cccc}
\hline S1 No. & Type of Extract & Amount of Extract $\mathbf{( g m})$ & \% Yield (\%w/w) \\
\hline 1 & Aqueous leaf extract & 2.850 & 14.25 \\
2 & Alcoholic leaf extract & 4.254 & 21.25 \\
3 & Aqueous fruit pulp extract & 1.421 & 7.105 \\
4 & Alcoholic fruit pulp extract & 1.821 & 9.105 \\
5 & Aqueous seed extract & 1.124 & 5.62 \\
6 & Alcoholic seed extract & 1.246 & 6.23 \\
\hline
\end{tabular}


Table 2: Results of phytochemical screening

\begin{tabular}{|c|c|c|c|c|c|c|c|}
\hline S1. No. & $\begin{array}{c}\text { Phyto- } \\
\text { Constituent }\end{array}$ & Alcoholic leaf extract & Aqueous leaf extract & $\begin{array}{l}\text { Alcoholic } \\
\text { Seed } \\
\text { extract }\end{array}$ & $\begin{array}{l}\text { Aqueous } \\
\text { Seed } \\
\text { extract }\end{array}$ & $\begin{array}{c}\text { Alcoholic } \\
\text { Fruit pulp } \\
\text { extract }\end{array}$ & $\begin{array}{c}\text { Aqueous } \\
\text { Fruit pulp } \\
\text { Extract }\end{array}$ \\
\hline 1 & Carbohydrate & + & + & + & + & + & + \\
\hline 2 & Flavanoids & + & + & - & - & + & + \\
\hline 3 & Alkaloids & + & + & - & + & - & + \\
\hline 4 & Glycosides & + & + & + & + & + & + \\
\hline 5 & Saponin & - & + & - & + & - & + \\
\hline 6 & Tannin & + & + & - & - & - & - \\
\hline 7 & Vitamin & + & + & + & + & + & + \\
\hline 8 & Amino acids & - & - & - & + & - & + \\
\hline 9 & Steroids & + & + & + & - & - & - \\
\hline
\end{tabular}

(+) Presence of phytochemical constituent, (-) Absence of phytochemical constitiuent

\section{Characterization of isolated compound}

The fraction obtained by column chromatography of ethanolic seed extract was characterized by qualitative chemical test for the presence of flavanoids, vitamin, glycoside, steroid, saponin etc (Table 3). The test showed positive result for steroidal glycoside.IR spectral data (Figure 2) showed peaks for aliphatic $\mathrm{CH}_{2}$ stretching $\left(2900 \mathrm{~cm}^{-}\right.$ $\left.{ }^{1}-3000 \mathrm{~cm}^{-1}\right)$ and five membered lactone ring $\left(1747.51 \mathrm{~cm}^{-1}\right)$.

Table 3: Result of chemical test of isolate obtained from column chromatography

\begin{tabular}{clc} 
S1. No. & Phytoconstituent & Result \\
\hline 1 & Flavanoids & - \\
2 & Vitamin & - \\
3 & Glycoside & + \\
4 & Steroid & + \\
5 & Saponin & - \\
\hline
\end{tabular}

(+) Presence of phytochemical constituent,

(-) Absence of phytochemical constitiuen

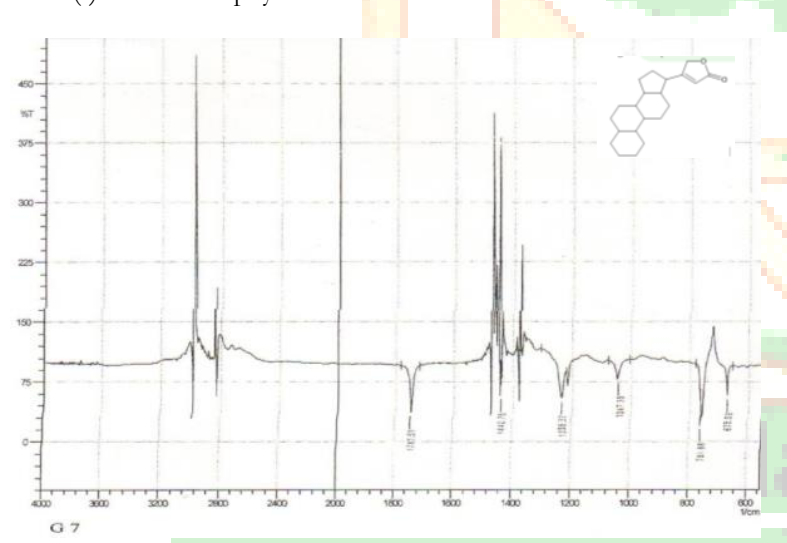

Figure 2: IR spectrum of isolated compound.

\section{Discussion}

In the present study the aqueous and alcoholic extracts of various parts of Psidium guajava were subjected to preliminary phytochemical analysis. Aqueous Leaf extract showed the presence of maximum number of phytoconstituents and alcoholic fruit pulp extract showed minimum constituents. Aqueous leaf extract showed the presence of Carbohydrates, flavanoids, alkaloids, glycosides, saponin, tannins, vitamins, steroids. It showed the absence of only amino acids, were as alcoholic leaf extracts showed the absence of saponins and amino acids. Aqueous fruit pulp showed the absence of tannins and steroids were as alcoholic fruit pulp showed the absence of alkaloids, saponins, amino acids, steroids etc. Aqueous seed extract showed the absence of flavanoids, tannins and steroids, were as alcoholic fruit extracts showed the presence of carbohydrates, glycosides, vitamin and steroids.

Even though percentage yield of alcoholic extracts were more aqueous extracts contained more number of active principles, so aqueous extracts should exhibit more pharmacological activity than alcoholic extracts, which has to be confirmed by pharmacological screening. The fraction obtained by column chromatography of ethanolic seed extract was characterized by qualitative chemical test for the presence of flavanoids, vitamin, glycoside, steroid, saponin etc. The test showed positive result for steroidal glycoside. IR spectral data showed that the compound contains a lactone ring. So according to above observations from chemical tests and IR spectrum it is possible that isolated compound contains following structure.

\section{Conclusion}

The objective of the study was to perform phytochemical screening of alcoholic and aqueous extracts of various parts of Psidium guajava, to isolate the active principles by column chromatography and to characterize the isolated compounds by chemical tests and IR spectroscopy.

Tender leaves, fruit pulp and seeds were used for extraction process. Aqueous and alcoholic extracts were prepared by soxhlet extraction method. Alcoholic extracts were obtained in more proportion compared to aqueous extracts. The phytochemical investigation showed the presence of glycosides, flavanoids, alkaloids, saponins, vitamin, carbohydrate, amino acid in the extracts in various proportions. Aqueous Leaf extract showed the presence of maximum number of phytoconstituents and alcoholic fruit pulp extract showed minimum constituents. Since aqueous extracts shows more number of active principles pharmacological evaluation of aqueous extract may show more activities than alcoholic extracts which has to be confirmed by pharmacological studies. 
Alcoholic seed extracts were subjected to column chromatography and qualitative chemical test and IR spectroscopy of the isolated compound showed that the compound may be a steroidal glycoside or the compound has a steroidal nucleus with a lactone ring. There is a need to confirm the structure of isolated compounds by using more advanced techniques such as mass spectroscopy and X-ray diffraction spectroscopy.

\section{References}

1. Ali Mohammad, "Pharmacognosy and plant cultivation", Vol. 2, New Delhi, CBS publishers and distributors, 2008, 1-18.

2. Dweck C. Antony "A review of guajava, FLS FRSC FRSH, Dweck Data.

3. Ojewole, John A O, Emmanuel O Awe, Witness D $\mathrm{H}$ Chiwororo, "Antidiarrhoeal activity of Psidium guajava Linn. (Myrtaceae) leaf aqueous extract in rodents", Journal of smooth muscle research, 44. 6, (2008),195-207. Online

4. Antonio Nei Santana Gondim, Vanda Rodrigues de Oliveira, Sellyanna Domeny dos Santos, Bagnólia Araújo da Silva, Carla Maria Lins de Vasconcelos, Eduardo Antonio Conde-Garcia "Extract from leaf of Psidium guajava L depresses the guinea pig atrial contractility by interfering with potassium and calcium channels", Brazilian Journal of Pharmaceutical Sciences, 45, 3, (2009), 483-489, online

5. Harborne J. B, Phytochemical method, a guide to modern technique of plant analysis $3^{\text {td }}$ edition, 1998, Springer (India) Pvt. Ltd, New Delhi, 4-30

6. Khandelwa K.R, "Practical Pharmacognosy" $4^{\text {th }}$ edition, Published by Nirali Prakashan, oct 2005, 183-184,149-156.

7. "The wealth of India" A dictionary of Indian raw materials \& industrial products, 4, J-Q Published and Printed by National institute of science communication and information resources council of scientific \& industrial research (CSIR), reprinted 2006, 411-415.

\section{Cite this article as:}

Lincy Joseph, Mathew George, Gurcharan Singh, Prabha Mathews. Phytochemical investigation on various parts of Psidium guajava. Annals of Plant Sciences 5.2 (2016): 1265-1268.
Source of support: Nil

Conflict of interest: None Declared 